\title{
Health care for foster kids: Fix the system, save a child
}

Previously published at www.cmaj.ca

$\mathrm{M}$ ore than 100000 children and youth in Canada are under the protection of child and family services and it comes as no surprise that many of them arrive there with emotional, physical or behavioural problems that need to be addressed.

What is astounding is that one of the richest countries in the world doesn't provide these children with supportive health care that could mitigate or, even better, prevent some of the devastation caused by parental abuse or neglect, alienation from family and becoming part of a system outside of the mainstream.

Instead, foster parents - and, subsequently, adoptive parents or guardians - are left to struggle with the consequences. For example, a recent study of girls aged 4 to 17 years in foster care who had been previously sexually abused found that all of them showed sexually abusive and inappropriate behaviour toward other children. ${ }^{1}$ A study in Washington State found that $72 \%$ of foster children had emotional disturbances that were indistinguishable from those of children being cared for in the most intensive mental health program. ${ }^{2}$ The multigenerational Adverse Childhood Experiences Study showed that between one half and two-thirds of serious drug abuse problems in adults in the United States are related to childhood experiences of abuse, neglect and household dysfunction - all factors that lead to placement in foster care. ${ }^{3}$ Furthermore, recent research in neurobiology has found that child abuse leads to epigenetic changes that can be passed from generation to generation. ${ }^{4}$

It's also no secret that lack of stability and permanency - in many jurisdictions, children and youth in care are moved 3 to 7 times - have a profoundly negative impact, setting the stage for depression, behavioural and relationship difficulties and myriad other problems, including academic failure and adolescent pregnancy. ${ }^{5}$

These children need long-term, consistent medical and mental health care to mitigate the consequences of abuse and neglect. They do not get it. One of the reasons is that with the moves from foster home to foster home, any health care efforts to help mitigate the consequences of earlier problems is sabotaged. Specific treatment programs are interrupted and long-term professional followup is next to impossible.

Another reason is that simply being in foster care confounds continuity of physical and mental health care. Foster parents often know only limited details of the child's medical history and even less about the biological family. Privacy and confidentiality issues abound. Misplaced or lost records of health care and education are the norm as the child or youth moves through the foster system. Longitudinal checkups by a single multidisciplinary team of health care providers almost never happen, even though fostered children are at far higher risk for serious disorders, including mental illnesses, than children who live in stable families. ${ }^{2,5}$

But when physical tracking of these children is inconsistent, how can we possibly begin to monitor problems in their mental and physical health or detect possible new medical issues?

A study examining the long-term health-related effects of foster care programs in the Pacific Northwest of the United States has shown that negative mental and physical outcomes among adults fostered as children were significantly reduced in systems where highly trained staff with low caseloads had access to high-quality services.
In Canada, we need to create an integrated approach to the delivery of programs and services that encompasses all of the needs of children in care. Timeliness and accessibility are key to the success of such an approach. This system would require:

- Better collaboration, such as structured meetings that include representatives of foster care and other social services, the criminal justice system, health care and education, with maximal efforts to optimize foster placements and minimize moves.

- A universal or portable health record, accessible by all providers of health, social and educational services. This record would help ensure that, if a child is moved, his or her records would remain accessible and the chain of treatment would not be interrupted.

- Specific multidisciplinary clinics, comparable to clinics providing complex care for chronic illnesses in children's hospitals throughout Canada. These clinics could offer supportive and nurturing environments, familiarity and continuity, thereby building trust and confidence for the child or youth and for foster care providers.

- A system to monitor supportive care of foster children and its outcomes in an open and transparent way to ensure we can measure results and create the most effective programs.

Outcomes for children and youth in foster care are too often tragic. We end up paying a substantial price, primarily in the loss of productive young lives, but also, for many, in the use of the criminal justice system and the need for long-term mental and physical health care.

It is time for our governments, institutions and health care providers to commit to building these children and youth instead of trying to fix them as adults.

\section{Paul C. Hébert MD MHSc}

Editor-in-Chief

Noni MacDonald MD MSc

Section Editor, Public Health

CMAJ

Editorial advisory team: Ken Flegel MDCM MSc and Joan Ramsay BA

Competing interests: See www.cmaj.ca/misc/edboard.shtml

Cite as CMAJ 2009. DOI:10.1503/cmaj.091627

\section{REFERENCES}

1. Dowdell EB, Cavanaugh DJ, Burgess AW, et al. Girls in foster care: a vulnerable and high-risk group. MCN Am J Matern Child Nurs 2009;34:172-8.

2. Trupin EW, Tarico VS, Low BP, et al. Children on child protective service caseloads: prevalence and nature of serious emotional disturbance. Child Abuse Negl 1993; 17:345-55.

3. Dube SR, Felitti VJ, Dong M, et al. Childhood abuse, neglect, and household dysfunction and the risk of illicit drug use: the adverse childhood experiences study. Pediatrics 2003;111:564-72.

4. Anda RF, Felitti VJ, Bremner JD, et al. The enduring effects of abuse and related adverse experiences in childhood. A convergence of evidence from neurobiology and epidemiology. Eur Arch Psychiatry Clin Neurosci 2006;256:174-86.

5. World Health Organization. Krug EG, Dahlberg LL, Mercy JA, et al., editors. World report on violence and health. Geneva (Switzerland); The Organization; 2002. Available: www.who.int/violence_injury_prevention/violence/world_report/en/ (accessed 2009 Sept. 10).

6. Kessler RC, Pecora PJ, Williams J, et al. Effects of enhanced foster care on the long-term physical and mental health of foster care alumni. Arch Gen Psychiatry 2008;65:625-33. 